\title{
Towards a hybrid model for the cryopreservation of umbilical cord blood stem cells
}

\section{Zafiris Polymenidis* and George P. Patrinos ${ }^{\ddagger}$}

In a recent article (Sullivan, M. J. Banking on cord blood stem cells. Nature Rev. Cancer 8, 555-563 (2008)) $)^{1}$, Michael J. Sullivan argues that "... in the absence of any published transplant evidence to support autologous and non-directed family banking, commercial cord banks currently offer a superfluous service." Umbilical cord blood (CB) is a unique part of a baby's body that, if discarded - a decision that cannot be made by the child - is impossible to retrieve. Currently, following the documented success of bone marrow and peripheral blood transplantations, both allogeneic and autologous, there are numerous commercial and public CB stem cell cryopreservation banks, a fraction of which indeed offer services of questionable quality.

In general, a CB unit can be cryopreserved in public and private CB banks, exploited in non-profit or commercial research institutes with consent, or discarded after delivery. The latter occurs in $\sim 99 \%$ of the cases - 130 million CB units annually. Currently, there are 314,000 CB units available in the World Marrow Donor Association (WMDA) for public storage and more than $800,000 \mathrm{CB}$ units in private CB banks. Presently, there are not enough resources to accommodate, test, process and store CB units from all 27,000 births each day in the United States, Europe and Canada and 356,000 births daily all over the world. That is the reason why, in its 2008 annual meeting, the WMDA established an ad hoc ethics subcommittee to determine the combination of private and public $\mathrm{CB}$ banking and to consider types of $\mathrm{CB}$ banking models, based on patient priority, conditional donation and CB unit sharing. Similarly, the European Group on Ethics in Science and New Technologies, under directives 2004/23/EC, 2006/17/EC and 2006/86/EC, does not discourage private $\mathrm{CB}$ banking and does not make any distinction between public or private $\mathrm{CB}$ banks for allogeneic and autologous transplantations, respectively, particularly as the latter case guarantees not only the graft's survival, due to histocompatibility, but also stem cell availability. In both cases, the same requirements for accreditation, unit designation, authorization and licensing of the tissue and cell preparation process and control must apply, based on a single European coding system.

Under these conditions, the hybrid private-public banking model for CB storage arises as a potential solution ${ }^{2}$. Alternatively, cryopreservation of CB in strictly accredited private or public CB for autologous usage can be subsidized by insurance companies or governments. The solution may lie in Homer's words: "If many men collocate, they'll tell different opinions. Pay attention to the best one."

*National Peripheral Tissue Typing Laboratory and Immunology Department, Hippokration General Hospital, Thessaloniki, Greece.

${ }^{\ddagger}$ Erasmus MC, Faculty of Medicine and Health Sciences, MGC-Department of Cell Biology and Genetics, Rotterdam, the Netherlands. e-mails:panmag@otenet.gr; g.patrinos@erasmusmc.nl

1. Sullivan, M. J. Banking on cord blood stem cells. Nature Rev. Cancer 8, 555-563 (2008).

2. Fisk, M. $\&$ Atun, R. Public-private partenship in cord blood banking. Br. Med. J. 336, 642-644 (2008). 